\title{
Deep Sea Net: an affordable, and expandable solution for deep sea sensor networks
}

\author{
P. Valdy, V. Ciausu, P. Léon, P. Moriconi, V. Rigaud \\ Ifremer (France) \\ Y. Hello, P. Charvis, A. Deschamps \\ Géosciences Azur (Observatoire Océanologique de Villefranche : France) \\ C. Sillans \\ IFOTEC (France)
}

\begin{abstract}
Deep Sea Net is a new concept of deep sea sensor network built from fiber optic micro cable and battery operated IP access nodes. Deep Sea Net fiber optic transport segments are deployed directly from a standard ROV, avoiding the use of a costly cable layer ship. Deployment skid is abandoned on user site ready to connect local sensors and next transport segment. Deep Sea Net is a low consumption network which can be waked on user (or sensor) demand. Lithium batteries and fine power management will give 10 years of autonomy with $1 / 4$ of hour operation per day. The innovative approach of Deep Sea Net will permit to build, extend and maintain future sensor networks at very competitive prices.
\end{abstract}

\section{NETWORK CONCEPT}

Deep Sea Net is a new concept of deep sea sensor network, to be installed beyond 1500 meters depth for servicing smart IP sensors (Fig.1).

Deep Sea Net is built from fiber optic micro cable (FOMC) and battery operated switches (IP Nodes) for long distance transport and local IP sensor interconnection.

Deep Sea Net is deployed, extended and maintained with all sensor suite with a standard ROV.

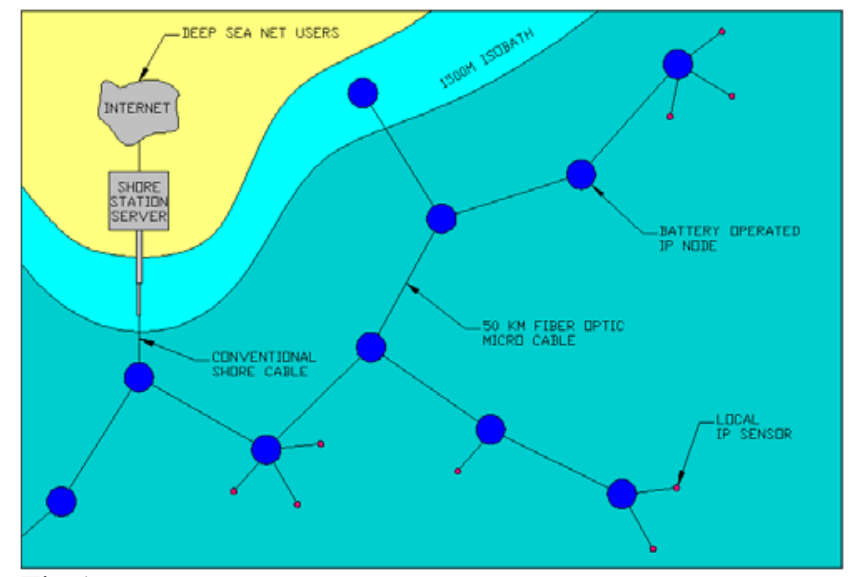

Fig.1

\section{FIBER OPTIC MICRO CABLE}

\section{A. FOMC justification}

In deep sea, the risk of cable damage due to anchoring, fishing activity or fish bites is very limited. When laid beyond 1500 meters depth, most of telecom cables have no external armor above high voltage insulation and are not buried. External protection is not critical in such depths.
Telecom cables are laid from the surface. They need to be dense and strong to support laying forces induced by current, heave and depth. If the cable is laid directly above the bottom, density and internal reinforcement are not critical.

Telecom networks never sleep. Repeaters need to be powered all the time. If network is operated only part of time, repeaters may be powered with batteries and copper and high voltage insulation are not necessary.

Within above considerations a 2 millimeter light cable is conceivable. A 50 kilometers cable spool may interconnect user sites and match with repeater spanning. Such little and light spool is compatible with standard ROV handling capacities.

\section{B. FOMC technical isuues}

Two fibers is the general standard for long distance IP transport. However for simplifying Deep Sea Net connectors, bi-directional transmission with single fiber is preferred.

Loose metal tube structure for fiber protection seems inevitable (no water ingress, no hydrogen effect, no fiber stress). This solution will allow to keep, in the long term, attenuation performances on long distance transport segments.

For corrosion aspects, 316 stainless steel is preferred than 304, but Inconel or Hastelloy may be a better choice in the future.

The choice of the final cable structure has been very difficult. Several longitudinal reinforcement have been evaluated (second metal tube plus polyamide jacket or high performance Liquid Crystal Polymer jacket). Finally, glass fiber in epoxy matrix (FRP) plus tight polyamide jacket (for improving bamboo structure cohesion and friction factor) has been selected (Fig.2) for a light, strong, stiff, elastic and low torque cable.

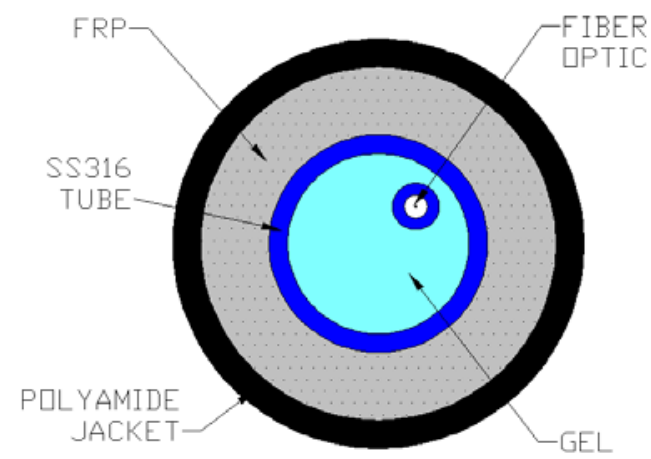

Fig.2 


\section{FOMC comparison with standard telecom cable}

The following table compares general characteristics of Deep Sea Net FOMC with low weight telecom cable.

\begin{tabular}{|l|c|c|}
\hline Cable & LW Telecom & FOMC \\
\hline Construction & $\begin{array}{c}\text { 12 FO in SST* } \\
\text { steel armor } \\
\text { copper tube } \\
\text { PE* jacket }\end{array}$ & $\begin{array}{c}\text { 1 FO in SST* } \\
\text { FRP* armor } \\
\text { PA* jacket }\end{array}$ \\
\hline Application & $\begin{array}{c}\text { Light Weight cable } \\
\text { for repeated } \\
\text { telecommunications } \\
\text { beyond 1500m }\end{array}$ & Deep Sea Net \\
\hline Diameter (mm) & 17 & 2.2 \\
\hline Breaking load (daN) & 7000 & 200 \\
\hline Weight (kg / 50 km) & 25000 & 425 \\
\hline Volume (liters / 50 km) & 14500 & 242 \\
\hline Cost factor & 1 & $1 / 6$ \\
\hline $\begin{array}{l}\text { SST: Stainless Steel Tube } \\
\text { FRP: Fiber Reinforced } \\
\text { Polymer } \\
\text { PE: Polyethylene } \\
\text { PA: Polyamide }\end{array}$ & & \\
\hline
\end{tabular}

\section{IP NODE}

\section{A. Electronic}

Electronic made by IFOTEC integrates in one single board (Fig.3):

\section{- 100 Mbps ADM 6999 Ethernet switch}

- $\quad 3 x$ 100FX ports for main and secondary transport (bi-directional transmission: $1530 \mathrm{~nm} / 1570 \mathrm{~nm}$ )

- $\quad 3 x$ 100TX ports for local applications (with $24 \mathrm{~V}$ power over Ethernet for power or bi-directional wake up (over the two Ethernet twisted pairs)

- $\quad$ Node wake up circuit

- $\quad$ Programmable timer for adjustable time-out

- $\quad$ Micro-controller for node and port management

\section{B. Batteries}

Node is powered with lithium batteries $(7.5 \mathrm{~kg} /$ $5594 \mathrm{Wh}$ ). The consumption of the node is $0.5 \mathrm{~mW}$ in sleeping mode and $4 \mathrm{~W}$ in operation. This will give 10 years of autonomy with $1 / 4$ of hour communication per day.

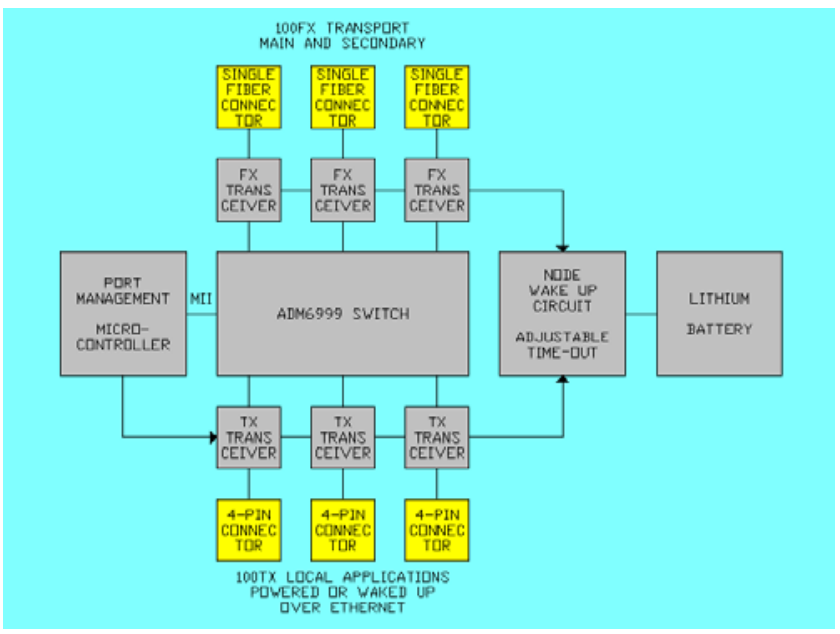

Fig.3

\section{Node integration}

The electronic board, the 6 battery packs and the 6 wet mateable connectors are integrated in a single flat titanium canister (Fig.4) resisting to 6000 meters depth pressure. The assembly is very compact and the weight in water is compatible with ROV handling capacity (40 daN).

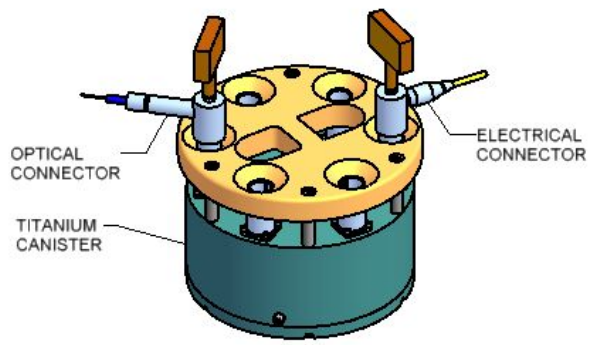

Fig.4

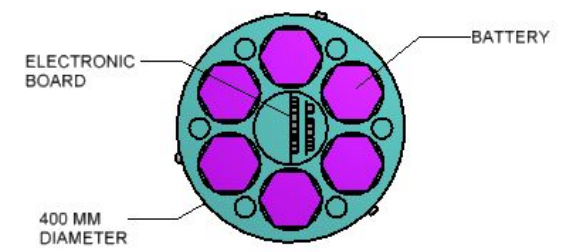

D. Wet mateable connectors

Electrical and optical connectors will be issued from a cooperation between Seacon Europe and Ifremer. The final objective is to develop, in the same small format, low cost and reliable wet mateable connectors.

Electrical connectors will integrate the Seacon Sea-Mate inserts $(4 \mathrm{x}$ gold plated contacts in nitrile housings). Such connectors are not insulated when not connected. Node management will allow to switch off data and power.

Optical connectors will use expanded beam technology. Specific inserts will integrate fiber optic collimators protected behind high pressure windows. Such connectors will have more losses than conventional ones. Deep Sea Net optical budget is sized in correspondence.

E. IP Node operation and management

Node wake up circuit and node timer are independent from the micro-controller.

Wake up circuit detects the arrival of the optical carrier of transport segments or the electric current of local applications.

It starts the timer and power up the switch and the attached micro-controller.

When powered up the micro-controller can respond to SNMP requests for node monitoring and port management.

Network supervisor may have access to each node via individual web pages (Fig.5) with following displays:

- $\quad$ Display of connection status

- Display of node status (Temperature / Voltage / Time-out setting: 2, 4, 8 or 16 minutes / Wake up source: FX or TX)

- $\quad$ Display of transport port status (Carrier sense)

- $\quad$ Port power and data status (need to be OFF when no connector and $\mathrm{ON}$ when application is powered up or wake up)

- $\quad$ Port wake up event status (need to be DISABLE if too much wake up events) 

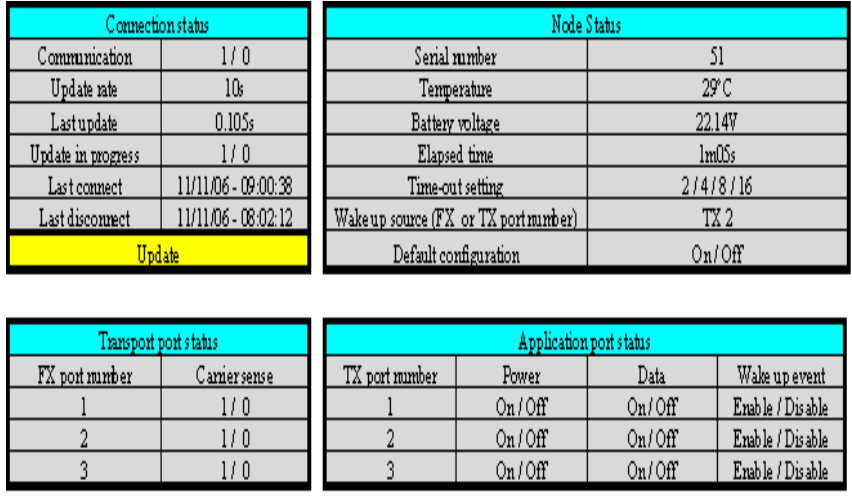

Fig.5

\section{DEEP SEA NET OPERATING PRINCIPLE}

\section{A. Sleeping mode}

All nodes are sleeping with $0.5 \mathrm{~mW}$ consumption and are ready to be waked by optical carrier from transport segments or electrical current from local applications.

\section{B. Normal operating mode}

Each day at fixed time (H0-T), any authorized user may connect on shore station server and demand to wake the network and its own application.

At $\mathrm{H} 0$, if at less one demand, shore station server wakes the shore station node. Then, each node is automatically waked one after the other by propagation of the optical carrier.

At $\mathrm{H} 0+\mathrm{T}$, network is operational and the demanded applications are waked via SNMP requests. Then, user which is informed that the network and its application are waked, connects to its application.

At $\mathrm{H0}+\mathrm{T} 0$ all nodes are independently powered down by time-out and Deep Sea Net returns in sleeping mode.

\section{Emergency operating mode}

Any authorized user may demand at any time to wake the network (within limited number of demands per year). Any battery operated application may demand to wake the network and send an E mail alarm to the application user (ex: Seismometer or tsunami sensor after event detection).

\section{APPLICATIONS AND INTERFACES}

There is two type of applications (Fig.6) which may be interfaced on Deep Sea Net:

- $\quad$ Remote powered applications

These applications may be powered on demand by $24 \mathrm{~V}$ phantom current through Ethernet pairs when IP Node is awake. These applications must have low power consumption (1W maximum). Being not autonomous they cannot record parameters out of daily operating periods. However it may be interesting to equip systematically each node with such application (ex: low power multi-parameter sensor: CTD sensor, current meter...).

Autonomous applications

Some applications need to monitor regularly their environment. They are powered by their own battery and the same Ethernet pairs can wake them by the intermediate of a $24 \mathrm{~V}$ relay for data file transfer. Other applications such seismometers or tsunami sensor need to send an alarm when an exceptional event is detected. In such case, these applications can wake up the node through the same Ethernet pairs. The clock of autonomous applications can be synchronized with NTP protocol.

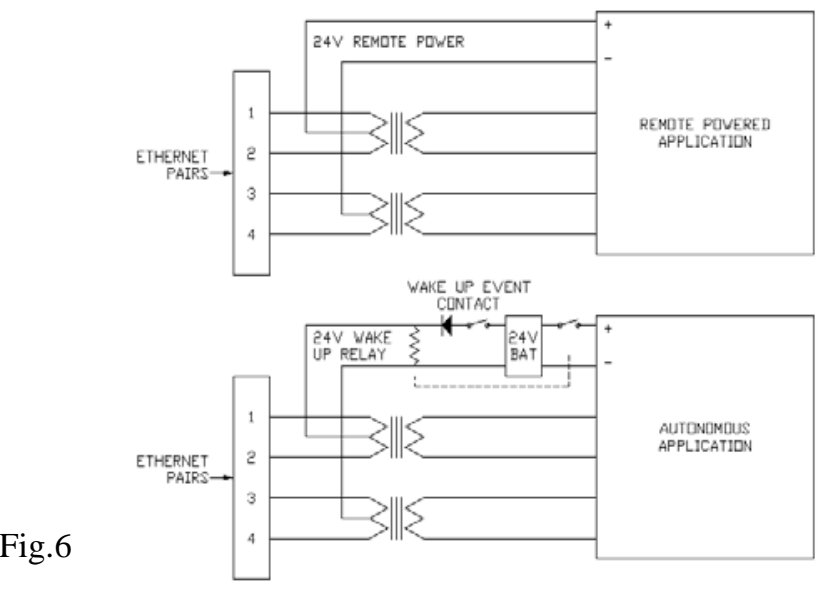

\section{DEEP SEA NET DEPLOYMENT}

\section{A. Deployment principle}

Deep Sea Net segments are deployed from site to site using deployment skids which integrate FOMC spool with attached rotating IP Node. Deployment skids are launched on each user site and abandoned on next one ready to connect sensors and next transport segments (main or secondary).

Network maintenance and extension, sensor maintenance and implementation may be done from standard academic ROV during annual oceanographic campaigns. If default on IP Node, it may be easily recovered and re-installed with the ROV. If default on the FOMC, segment has to be changed completely.

\section{B. Deployment skid}

Deployment skid (Fig.7) integrates following components:

\section{- $\quad$ Rotating spool}

Horizontal rotating spool is supported with roll bearings and has up to 55 kilometers FOMC capacity. IP node is fixed on top flange by the intermediate of a bayonet mounting. Simple rotating spool has been preferred than fixed spool with internal unwinding (torpedo pack like) or external unwinding (fishing reel like). Despite spool high inertia, cable loads will be limited in comparison with cable characteristics (2 daN during laying and 15 daN during maximum acceleration for 200 daN cable breaking load).

\section{Constant tension roller}

A spring actuated roller prevents the FOMC to be overloaded during acceleration or to be slack during deceleration ( 0.5 meter cable stroke).

- $\quad$ Automatic brake band

At the end of the stroke, to prevent any slack the roller actuates a brake band to brake the spool.

- Trench plow

For better FOMC protection a heavy knife is installed at the rear part of the deployment skid to burry the micro cable inside the sediment (trench section: $30 \mathrm{~mm}$ wide / $200 \mathrm{~mm}$ depth). A flexible and heavy hose is in charge of guiding smoothly the micro cable inside the trench. 
- $\quad$ Variable buoyancy

The skid is sent on the bottom under variable buoyancy in equilibrium between the buoyancy force and the reaction on the plow (120 kilograms). Due to the cable variable weight in water (initially: 230 kilograms), the buoyancy needs to be adjusted by filling a ballast as the cable is laid.

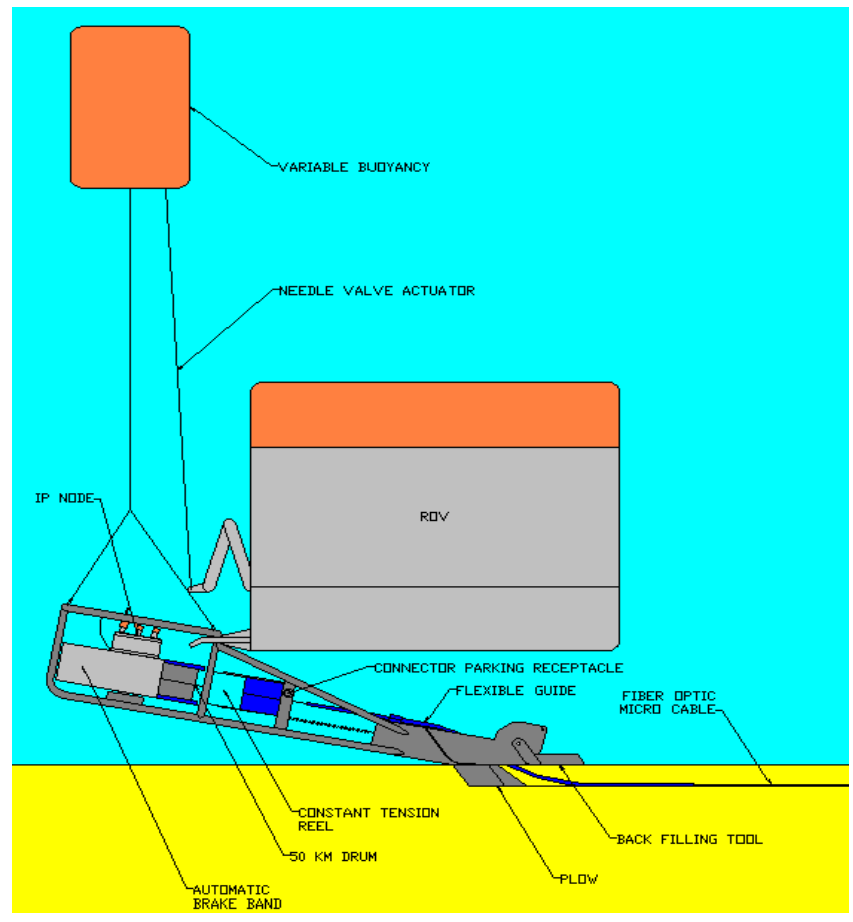

Fig.7

The ROV laying speed (1 knot) will allow to install a 50 kilometer segment per day.

The cable laying route, under full ROV control, will clear all significant obstacles on the bottom and the skid will be driven right near to the user spot (which is in comparison difficult to achieve with conventional junction boxes laid from the surface).

\section{DEEP SEA NET DEMONSTRATION}

Deep Sea Net demonstrator will be tested on Antares junction box (Fig.8). Antares is a neutrino telescope installed in Mediterranean sea, at 2400 meters depth, offshore Porquerolles island. Antares junction box is equipped with 16 electro-optic connectors and is connected to La Seyne sur Mer shore station with a 42 kilometers cable. Deep Sea Net will use one of these connectors.

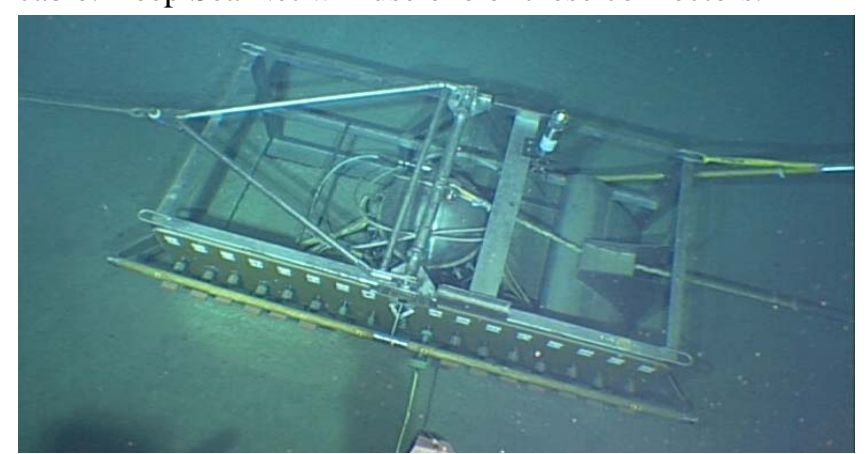

Fig.8
One ultra low power seismometer, developed by Geosciences Azur from the Observatoire de Villefranche will be connected to the demonstrator.

Deep Sea Net demonstrator is funded by the French National Research Agency (ANR) through the MOGLI project which is a cooperation between Géosciences Azur and Ifremer.

The final objective will be to propose an affordable solution for a seismometer network in Ligurian sea (offshore the city of Nice). This site is one of the key sites proposed by the EC ESONET project.

\section{CONCLUSION}

The author, as adviser of physician community for Antares marine architecture and as responsible of Antares sea operations, knows the costs and difficulties of such installations. Cable layer ships are expensive and difficult to schedule, junction boxes are heavy and risky to deploy, oil filled connectors are expensive and may experience failures. When problems occur, maintenance of such network is very difficult.

Telecom cable when used for shore to shore communications, are very reliable. When used for interconnecting deep sea junction boxes, the reliability is certainly more difficult to predict. Even with the hypothesis of 20 years life expectancy, annual ROV campaigns are still necessary for sensor suite maintenance and implementation.

Scientists who want to develop smart sensors should be interested by this alternative solution which can be installed, maintained and extended at affordable prices using their own naval equipment.

Deep Sea Net may be operated from conventional shore cable or offshore telecommunication buoy. It may also be operated as an extension of an existing scientific network. Applications may be oceanographic or homeland security. After demonstration, the technology, which is protected by Ifremer patents, will be transferred to the industry for the benefit of deep sea science applications.

\section{REFERENCES}

[1] Valdy, P. Réseau sous-marin profond et dispositif de deploiement. Patent Application Number: FR 0606292. 10/07/2006. Unpublished.

[2] Deschamps, A.; Hello,Y.; Charvis, P.; Dugué, M.; Bertin,V.; Valdy, P.; Le Van Suu, A.; Real, D. Broadband Seismometer at $2500 \mathrm{~m}$ Depth in the Mediterranean Sea. EGS - AGU - EUG Joint Assembly, Nice, France, April 2003.

[3] Anghinolfi, M.; Calzas, A. ; Dinkespiler, B.; Cuneo, S.; Favard, S.; Hallewell, G.; Jaquet, M.; Musumeci, M.; Papaleo, R.; Raia, G.; Valdy, P.; Vernin, P. The deep-sea hub of Antares neutrino telescope. Nuclear Instruments and Methods in Physics Research. 2006. 